\title{
Application of Resource Efficient and Cleaner Production Approach in the Accommodation Sector of the Balkan Region
}

\author{
Mariana Assenova ${ }^{1}, Z_{\text {dravko Georgiev }}^{2}$, Branko Dunjic ${ }^{3}$
}

\begin{abstract}
The aim of the paper is to present the results of the application of the RECP methodological approach in the accommodation sector of countries from the Balkan region - Croatia, Serbia, Montenegro and Albania. It is based on the experience from 2015 in 20 hotels (5 in each country), undergone detailed in-plant assessments. The methodology lays down on the understanding that RECP is a continuous application of an integrated preventive environmental strategy applied to processes, products and services to increase overall efficiency, and reduce risks to humans and the environment. Based on the obtained data for the material and energy flows, the paper provides a summary and analyses of the most often proposed and implemented measures. A set of absolute and relative indicators (KPIs) for resources use (energy and water consumption) and pollution generated (air emission and waste water) is used and the expected change due to the implementation of the accepted options is calculated. The performance of the accommodation facilities is compared to the international benchmarks available. The results of the study come to show the great potential of the accommodation sector for more sustainable production and outline the focal points of intervention needed.
\end{abstract}

Keywords: resource efficiency, cleaner production, monitoring, performance indicators, benchmarks, accommodation sector

\section{Introduction}

The Balkan region has always been considered as an important tourist destination as it borders the Mediterranean and the Black sea and has within its territory high and preserved mountains. As a crossroad of civilizations it represents a mixture of ethnic groups, co-existence of religions - Eastern orthodox, Catholic, Muslim and Jewish, and boasts with rich cultural heritage, folklore and traditions.

Tourism is an important economic sector of the discussed 4 Balkan countries - Albania, Croatia, Montenegro and Serbia, and shows significant development in the last two decades. Hotel bed capacity of Albania increased in the last 20 years 6,6 times from 2018 in 1995 to 13351 in 2014 (Table 1), but the peak was in 2011 when the beds in operation were almost 19000 . In Croatia the accommodation bed capacity increased steadily 1,5 times in the period 1995 - 2014, with a slight decrease in the period 2010-2013. In Serbia in 2011 the number of beds was slightly higher (127 664) compared to the beds available in 2014. Currently Croatia has the highest number of available beds - more than one million, in Montenegro and Serbia they are respectively around 160000 and 103000 , while Albania, in spite of the high growth rate, lags behind with only about 13350 bed capacity.

Sofia University, Social and Environmental Responsibility Center.

${ }^{2}$ Sofia Energy Agency - SOFENA, Social and Environmental Responsibility Center.

${ }^{3}$ National Cleaner Production Centre of Serbia, Faculty of Technology and Metallurgy. 
Table 1. Bed capacity, foreign arrivals and overnights (2014)

\begin{tabular}{|l|l|l|l|l|l|l|}
\hline & No of beds & $\begin{array}{l}\text { No of foreign } \\
\text { arrivals in } \\
\text { accommodation } \\
\text { establishments }\end{array}$ & $\begin{array}{l}\text { Total No of } \\
\text { overnights }\end{array}$ & $\begin{array}{l}\text { No } \\
\text { overnights of } \\
\text { foreigners }\end{array}$ & $\begin{array}{l}\text { Share of } \\
\text { overnights of } \\
\text { foreigners in \% }\end{array}$ & $\begin{array}{l}\text { No of } \\
\text { nights } \\
\text { per bed }\end{array}$ \\
\hline Albania & 13351 & 161000 & 459000 & 260000 & $57 \%$ & 34 \\
\hline Croatia & 1002000 & 11623000 & 66484000 & 61324000 & $92 \%$ & 66 \\
\hline Montenegro & 159347 & 1350297 & 9553783 & 8596656 & $90 \%$ & 60 \\
\hline Serbia & 102940 & 1028732 & 6086275 & 2161054 & $36 \%$ & 59 \\
\hline Total & 1277638 & 14163029 & 82583058 & 72341710 & $88 \%$ & 65 \\
\hline
\end{tabular}

Source: National statistical institutes of Albania, Croatia, Montenegro and Serbia

Co-related with the bed capacity are the foreign arrivals in accommodation facilities and the registered overnights (Table 1). The countries attracted more than 14 million overnight foreigners in 2014 with an average stay of 5 nights. Most efficient is the operation of the accommodation establishments in Croatia with 66 nights per bed, slightly less efficient are those in Montenegro and Serbia (about 60) and Albania demonstrates rather inefficient and highly seasonal operation with only 34 nights per bed. At the same time it is peculiar that Croatia and Montenegro are predominantly serving the international market (more than 90\% overnights of foreigners), while in Albania the national and international markets are in balance, and in Serbia tourism is prevailingly domestic.

With the exception of Serbia (6\%), in 2014 the total contribution of tourism to GDP is relatively very high in all other countries - between 20 and $23 \%$, and the forecast is for steady growth till 2026 (fig. 1). The direct contribution to GDP is also very high in Croatia (10\%) and Montenegro (10\%), moderate in Albania (6\%) and comparatively low in Serbia $(2 \%)$, but the economic importance of tourism for the last two countries is evident, due to the high share of indirect and induced contribution.

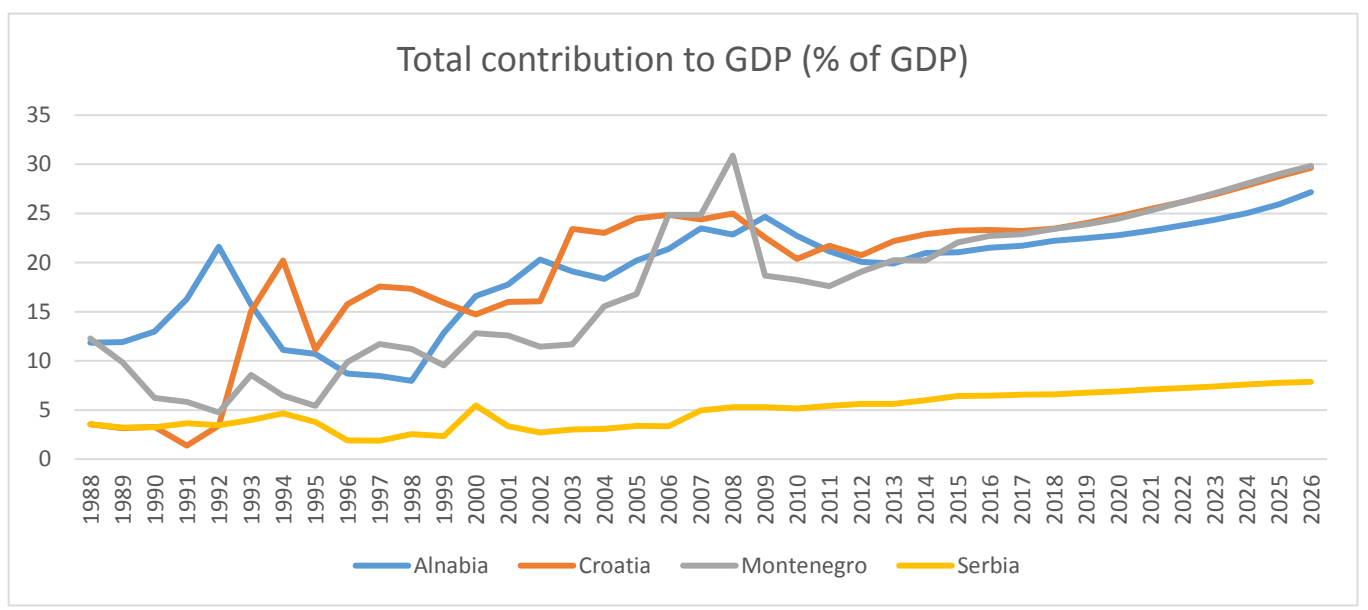

Fig. 1. Total contribution to GDP (\% of GDP)

Source: World Travel and Tourism Council 


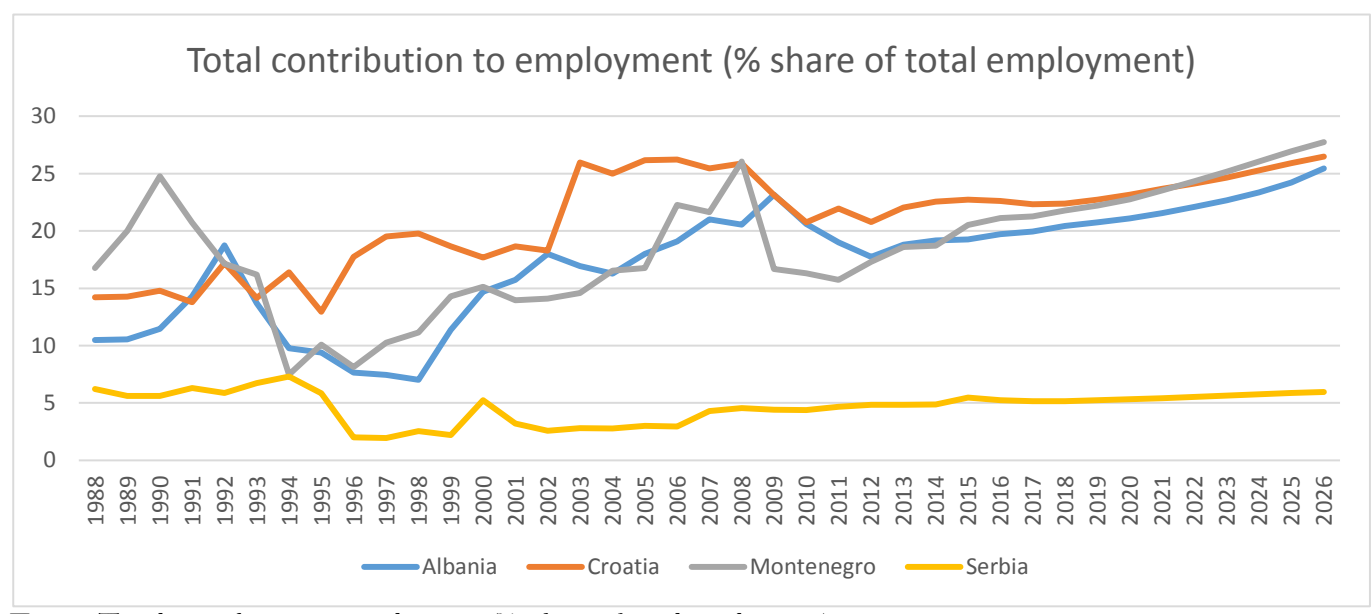

Fig. 2. Total contribution to employment (\% share of total employment)

Source: World Travel and Tourism Council

In terms of employment the total contribution of tourism in 2014 is also very high in Croatia, Montenegro and Albania (between 19 and 23\%), while in Serbia, although comparatively low - about $5 \%$, it is still substantial for national economy (fig. 2). The forecast is for slight increase in the period till 2026. The direct contribution to employment in 2014 is significant in Croatia and Montenegro- about 10-11\%, quite high in Albania - about 6\%, and rather low in Serbia - about 2\%.

As outlined above tourism is today one of the largest drivers of employment and development in the appointed countries, regarded as countries in transition (with the exception of Croatia, which is an EU member since 2013).But in many zones the construction and exploitation of tourist enterprises also lead to environmental problems such as huge and uncoordinated construction activities, large amount of unsorted wastes, inefficient water management and use of energy. Globally tourism is responsible for 5\% of the world's carbon dioxide (CO2) emissions, out of which hotels and other types of accommodation account for 1\% (Hotel Energy Solutions, 2011). Although comparatively small, footprint of tourism sector is important and has to be addressed. The EU Action Plan for Energy identifies the tertiary sector, including hotels, as having the potential to achieve 30\% savings on energy use by 2020 through energy efficiency and use of renewable energy - higher than savings from households (27\%), transport (26\%) and the manufacturing industry (25\%) (Hotel Energy Solutions, 2011).

As a methodology Cleaner Production (CP) was launched at UNEP's First International Advisory Seminar on preventive environmental management strategies in 1990. In 1994, a joint UNIDO-UNEP National Cleaner Production Centres' Programme (NCPC Programme) was launched with the objective of increasing the competitiveness and productive capacity of industry, specifically Small and Medium-sized Enterprises (SMEs), through the implementation of CP and the application, adaptation and diffusion of Environmentally Sound Technologies (ESTs). UNIDO and UNEP have further extended the scope of their joint programme to Resource Efficient and Cleaner Production (RECP) (2009-2014) to associate CP more profoundly with today's and 
tomorrow's most pressing environmental and resource use challenges, at the local, national and global scales (Viera and Amaral, 2016; Luken et al., 2016).

In 2013 UNIDO launched the project "Regional networking for strengthening cooperation and fostering transfer and adaptation of resource efficient and cleaner production (RECP) in the countries of South-Eastern Europe", in which Sustainable Tourism was one of the priorities. The purpose of UNIDO through the application of the RECP approach in tourism industry of the region was to ensure that companies continuously reduce the environmental impacts of processes and products through using resources more efficiently, phasing out toxic substances, and substituting fossil fuels with renewable energy sources, improving occupational health and safety, taking increased producer responsibility and reducing overall risks. The project was based on UNIDO's experiences in Bulgaria and Romania where in the period 2007-2010 similar projects were successfully implemented. The methodology was also implemented in the accommodation sector of Sri Lanka, Egypt, Morocco, Latin America, etc.

\section{Methodology}

The aim of the paper is to present the results of the application of the RECP methodological approach in the accommodation sector of countries from the Balkan region - Croatia, Serbia, Montenegro and Albania. It is based on the experience from 2015 in 20 hotels (5 in each country), undergone detailed in-plant assessments (Table 2). The hotels are predominantly of higher category (85\% are 4 -star hotels). Half of them a typical city hotels and the other 9 are located at the Adriatic coast, while one is on a lake shore. The hotels for summer recreation at the seaside are of greater capacity which results in a relatively high average capacity of the hotels in Croatia and Montenegro and far lower - in Serbia. The number of permanent employees varies depending on the seasonality of operation and the category of the hotels. In Albania and especially in Serbia, due to the high category of the assessed hotels and the location of some of them in the capital cities, the ratio of beds and employees indicates higher quality of service. In total the number of beds affected by the RECP measures is nearly 5000 and the employees - more than 1300 .

Table 2. Characteristics of the assessed hotels

\begin{tabular}{|l|l|l|l|l|l|}
\hline & Albania & Croatia & Montenegro & Serbia & Total \\
\hline No of assessed hotels & 5 & 5 & 5 & 5 & 20 \\
\hline Category & & & & & \\
\hline$-\quad$ 2- and 3-star & & 1 & 2 & & 3 \\
\hline - 4-star & 5 & 4 & 3 & 5 & 17 \\
\hline Location & & & & & \\
\hline - city/countryside & 2 & 2 & 2 & 4 & 10 \\
\hline - seaside/island/lake & 3 & 3 & 3 & 1 & 10 \\
\hline Average bed capacity & 243 & 334 & 300 & 93 & 242 \\
\hline Average No of employees & 78 & 80 & 49 & 57 & 66 \\
\hline
\end{tabular}

Source: In-plant assessment reports 
The methodology lays down on the understanding that RECP is a continuous application of an integrated preventive environmental strategy applied to processes, products and services to increase overall efficiency, and reduce risks to humans and the environment. It specifically works to advance the three dimensions of sustainable development in an integrated manner, by catalyzing (Joint Programme .., 2009):

- $\quad$ Production Efficiency through optimization of the productive use of natural resources (materials, energy and water) by enterprises and other organizations;

- Environmental Management through minimization of the impact on environment and nature, by preventing the generation of waste and emissions and improving the management and productive use of chemicals in enterprises and other organizations;

- Human Development through minimization of risks to people and communities from enterprises and other organizations and supporting their own development.

The hotel processes and services that are studied in detail are depicted on Fig. 3 (Selfassessment .., 2011).

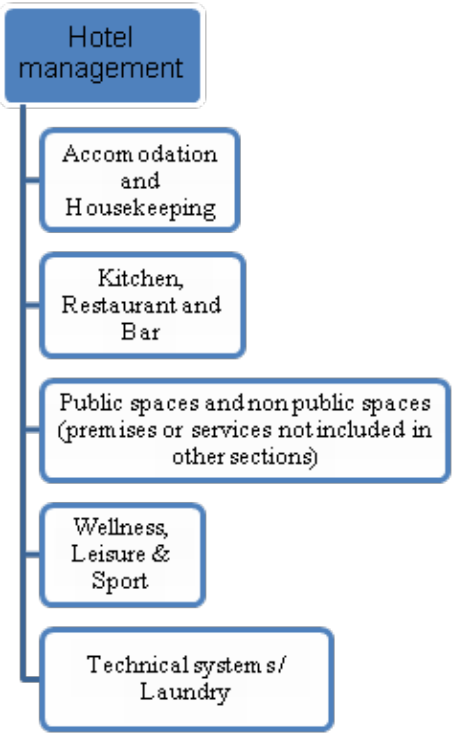

Fig. 3. Processes in a common accomodation establishment

In each hotel external consultants, together with designated staff members from all hotel departments conducted RECP assessment, analyzing the material and energy flows, elaborating and evaluating resource efficiency measures to be discussed with the management and owner and included into implementation plan.

Special focus was given to the calculation of key performance indicators (KPIs) to be used for benchmarking with other similar hotels and for monitoring and evaluation of the results of measures' implementation (Environmental..., 2006). Hotels were compared with accommodation sites from the same category of services and similar climate conditions abroad. The performance indicators were based on the overnights 
spent:

- $\quad$ Total energy consumption per guest night, $\mathrm{kWh} /$ guest night (kWh/gn);

- $\quad$ Total water consumption per guest night, $\mathrm{m}^{3} /$ guest night $(\mathrm{kWh} / \mathrm{gn})$;

- $\quad \mathrm{CO}_{2}$ emissions per guest night, $\mathrm{kgCO}_{2} / \mathrm{gn}$.

The European standard EN 16231:2012Energy efficiency benchmarking methodology was used in order to compare the specific energy consumption in the evaluated 4-star hotels. Energy efficiency benchmarking is defined as a process of collecting, analysing and relating performance data of comparable activities with the purpose of evaluating and comparing performance between or within entities. Benchmarking methodology model for the standard was applied including the following steps:

- $\quad$ Purpose and planning - hotels in high standard service category were selected (4-star with SPA and restaurants);

- Data collection and verification - RECP experts collected data for the reference year (2013 or 2014) from the accounting departments;

- Analysis and results - hotels were ranked according to their specific energy consumption and the results were studied and commented;

- $\quad$ Reporting - results were shared within participating hotels and presented at UNIDO meetings and workshops in the area of tourism.

\section{Outcomes}

\subsection{Workable RECP options and economic impact}

The structure of the RECP workable options by type and their economic impact is presented by country on fig. 4 and fig. 5, and generalized information is provided in Table 3. The highest number of options was generated by the consultants in Serbia (104), followed by Albania (64), Montenegro (48) and Croatia (39).

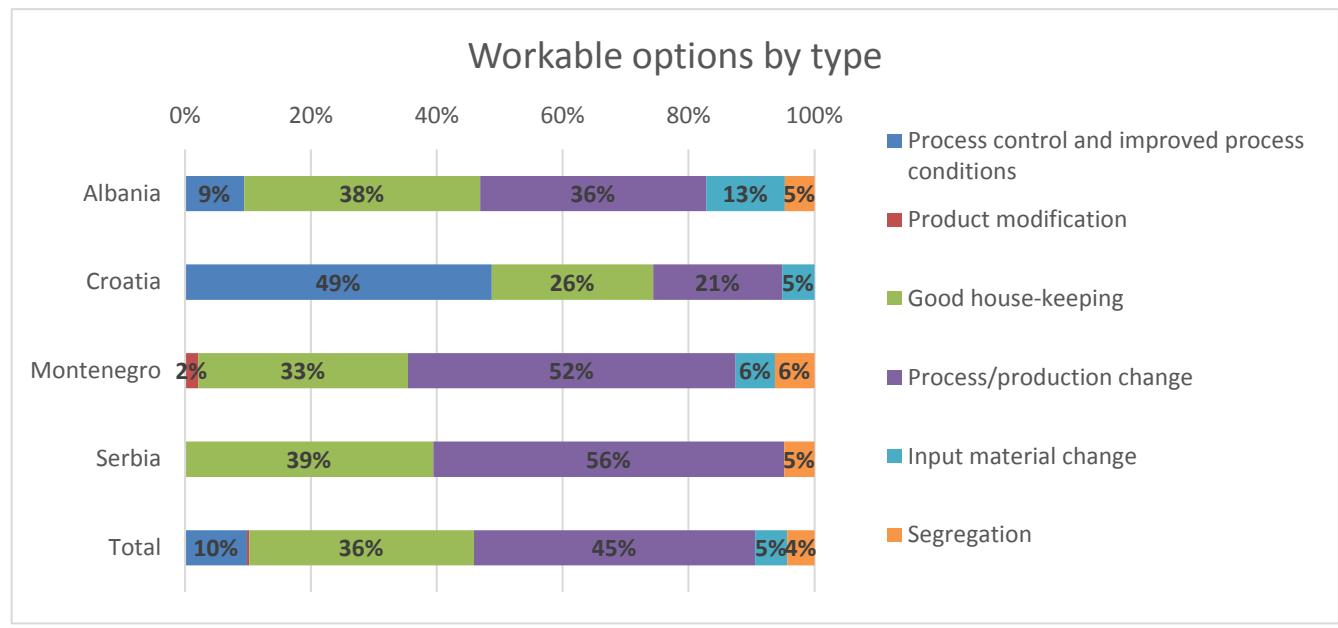

Fig. 4. Relative share of workable options by type

Source: In-plant assessment reports 
In general, most often proposed measures refer to the change in production process $(45 \%)$ and good house-keeping (36\%). 10\% of the proposed measures respond to the need to improve the process control or the process conditions. In a limited number of hotels the need to change the input material (5\% of options) or to organize the waste segregation ( $4 \%$ of options) was identified. In only one case product modification was proposed. As evident on fig. 4, there are substantial differences among countries. While in Croatia of highest importance are the measures related to process control and conditions, in Serbia, Albania and Montenegro of highest priority are the changes of production process. In all countries good house-keeping measures are about 1/3 of all proposed and accepted options.

The total amount of investments required is worth $€ 1,3$ million (Table 3). $90 \%$ of that money is needed for the options related to the change of production process. They include purchase of new equipment (e.g. of higher energy class) or technological change. Another $8 \%$ are necessary for the implementation of the measures related to the input material change - especially chemical products (cleaning, laundry and washing) and cosmetics. The improvements in process control and conditions and the good housekeeping measures are related to better organization and training of staff and do not require much investments. They include: regular check of double flushes in the bathrooms, taps and pipes for leakage, use of washing and laundry machines in full capacity, relocation of compressors from the refrigeration rooms, inform guests for the separation of waste and train the staff to do so, provide written information for guests to save water (including the change of towels), etc.

Table 3. Workable options by type, investments, savings and payback period

\begin{tabular}{|l|l|l|l|l|l|}
\hline No & Option type & $\begin{array}{l}\text { Number of } \\
\text { options }\end{array}$ & $\begin{array}{l}\text { Investment } \\
(\boldsymbol{€})\end{array}$ & $\begin{array}{l}\text { Savings } \\
(\boldsymbol{€} / \mathbf{y})\end{array}$ & $\begin{array}{l}\text { Average Payback } \\
\text { Period (y) }\end{array}$ \\
\hline 1 & $\begin{array}{l}\text { Process control and improved } \\
\text { process conditions }\end{array}$ & 25 & 12998 & 4104 & 3,2 \\
\hline 2 & Product modification & 1 & 3000 & 9583 & 0,3 \\
\hline 3 & Good housekeeping & 91 & 2871 & 43068 & 0,1 \\
\hline 4 & Process/production change & 114 & 1179037 & 505270 & 2,3 \\
\hline 5 & Input material change & 13 & 106887 & 37808 & 2,8 \\
\hline 6 & Segregation & 11 & 370 & 4025 & 0,1 \\
\hline & Total & $\mathbf{2 5 5}$ & $\mathbf{1 3 0 5} \mathbf{1 6 3}$ & $\mathbf{6 0 3 \mathbf { 8 5 8 }}$ & $\mathbf{2 , 2}$ \\
\hline
\end{tabular}

Source: In-plant assessment reports

The economic impact of workable options is considerable. The total savings are calculated to be about $€ 0,6$ million. The payback period is slightly more than 2 years, which makes the investment not risky. Greatest investment of nearly $€ 0,5$ million is needed in Montenegro, where two older 2-star hotels are assessed, while in Croatia and Serbia, despite of the different priorities, similar amounts of money are necessary - 
between $€ 0$,3and $€ 0,4$ million. In Albania, where all involved hotels are 4-star and recently renovated the investments required are smallest in size $-€ 0,12$ million.

The analysis of the proposed and implemented measures shows that organizational and good house-keeping measures, which involve personnel training and information for the guests, and monitoring of energy and resources have the highest effect and very fast payback of the investments - up to 2 years. Options for lightening system optimization and water savings have payback period from 2-3 months to 2-3 years, excluding cases where new installations and major changes are necessary. The improvement of HVAC systems, as well as equipment changes are also often recommended measures. The size of investments in reduction of energy and water consumption for the different accommodation sites varies between $€ 2500$ and $€ 200$ 000. The higher values refer to the implementation of renewable energy sources (solar thermal, biomass, heat pumps).

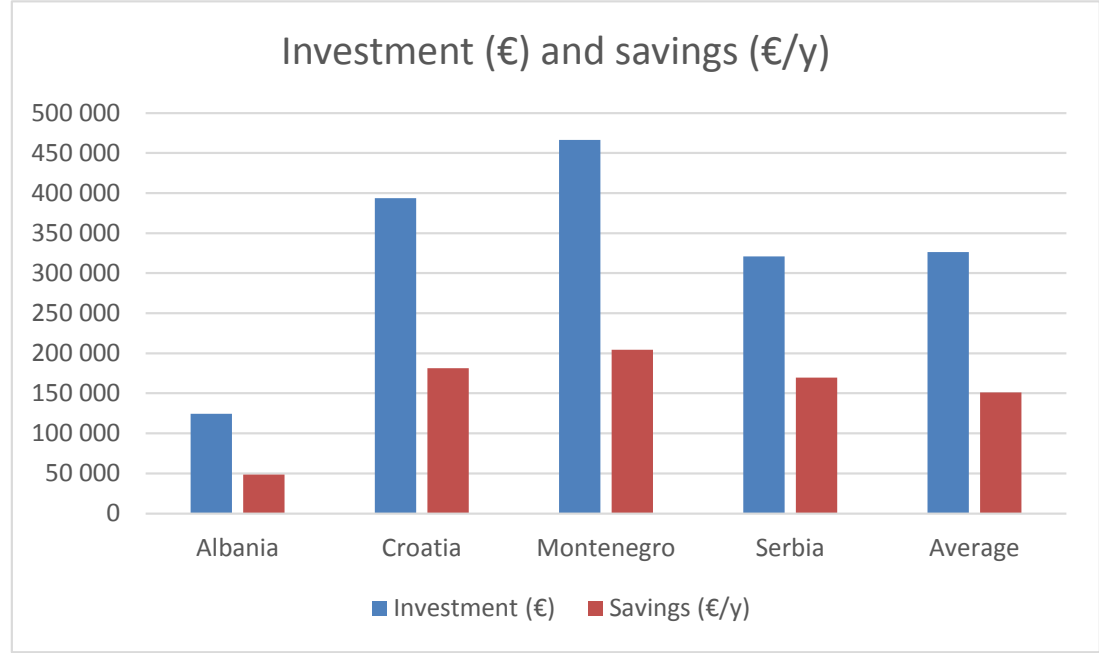

Fig. 5. Investments and savings of the workable options

Source: In-plant assessment reports

\subsection{Key performance indicators and carbon footprint}

Absolute and relative indicators were used to evaluate hotels in terms of resource efficiency. Energy consumption was compared to the realized guest overnights. Variations are high as half of the hotels have less energy consumption per overnight than the average and the others have excessive consumption. Results are commented in point 3.3 . 


\section{Energy consumption vs overnights}

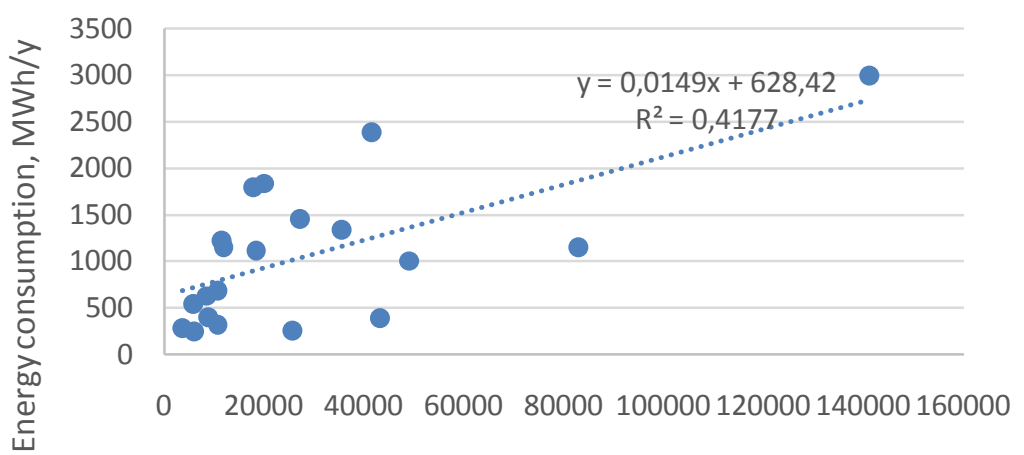

Overnights

Fig. 6. Comparing energy consumption and overnights for the participating hotels

Source: In-plant assessment reports

Expected energy savings reported reach $34 \%$ as none of the experts recommended energy efficient renovation of the facilities. Such a measure was commented for the old city hotels but rejected at this stage due to the high cost of investments and possible complications due to architectural elements on the façade and need of permits by cultural heritage institutions. Renewable energy sources like solar thermal collectors, biomass boilers and heat pumps were proposed for the seaside hotels (utilization of solar energy for domestic hot water) and to replace oil/gas boilers in the year-round hotels.

The average carbon footprint indicator is $17 \mathrm{kgCO}_{2} /$ overnight and varies from 2 to 65 $\mathrm{kgCO}_{2}$ /overnight. Emission factors for electricity defer a lot by country as for Albania where hydropower stations produce almost $100 \%$ of electricity it is $0.009 \mathrm{kgCO}_{2} / \mathrm{kWh}$ and reaches $1 \mathrm{kgCO}_{2} / \mathrm{kWh}$ in Serbia where the share of lignite in electricity production is high. $\mathrm{CO}_{2}$ emissions reduction is proportional to energy saving but can be considerable in case of introduction of renewable energy technologies (solar thermal, biomass).

Water consumption varies between 165 and 605 1/overnight as in the city hotels and hotels with swimming pools it is higher. Water savings are considered as important both for reduction of wastewater discharged in the sewage systems and energy consumption for heating of the domestic hot water (DHW). Solar thermal systems for DHW are technically and financially feasible in all countries in the region. Water-saving water mixers and restrictors as well as balancing the system are options considered in most of the hotels as it can reduce the water consumption up to $40 \%$.

Waste generated per guest overnight stay vary between $0,91 \mathrm{~kg} / \mathrm{gn}$ and $3.69 \mathrm{~kg} / \mathrm{gn}$. Waste segregation and recycling are measures proposed in most of the participating hotels. The waste problem is actual in all Balkan countries where the EU directives and waste management principles are in process of development and implementation. The potential for waste reduction is estimated to be $25-30 \%$ in some of the sites. 


\subsection{International benchmarking}

KPI for the selected hotels were compared to the benchmarks for 4-stah hotels according to the table below (Self-assessment .., 2011).

Table 4. Key performance indicators

\begin{tabular}{|c|c|c|c|c|}
\hline Indicator & Unit & Benchma & res & Average for the hotels \\
\hline \multirow{3}{*}{$\begin{array}{l}\text { Specific energy } \\
\text { consumption }\end{array}$} & \multirow{3}{*}{$\mathrm{kWh} / \mathrm{gn}$} & $<40$ & Satisfactory & \multirow{3}{*}{55.16} \\
\hline & & $40-70$ & High & \\
\hline & & $>70$ & Excessive & \\
\hline \multirow{3}{*}{$\begin{array}{l}\text { Specific water } \\
\text { consumption }\end{array}$} & \multirow[t]{3}{*}{$\mathrm{m} 3 / \mathrm{gn}$} & $<0.59$ & Satisfactory & \multirow[t]{3}{*}{0.357} \\
\hline & & $0.60-0.75$ & High & \\
\hline & & $>0.75$ & Excessive & \\
\hline \multirow{3}{*}{$\begin{array}{l}\text { Specific } \\
\text { generated }\end{array}$} & \multirow[t]{3}{*}{$\mathrm{kg} / \mathrm{gn}$} & $<0.99$ & Satisfactory & \multirow[b]{3}{*}{1.83} \\
\hline & & $1.00-1.50$ & High & \\
\hline & & $>1.50$ & Excessive & \\
\hline
\end{tabular}

Most of the hotels have higher values of the KPIs than the satisfactory benchmarks which indicates potential for implementation of RECP measures and achieving savings of energy, water and materials in the accommodation sector.

All 20 hotels took part in the benchmarking process for energy efficiency according to EN 16231:2012 standard as the 2-star hotels declared that their services corresponded to those of 4-star. Hotels are ranked according to their specific energy consumption defined as $\mathrm{kWh} /$ overnights. The values vary a lot from about 8 to about $100 \mathrm{kWh} /$ overnight. The accommodation sites with seasonal peak in summer have better performance as in the off-peak period they manage to reduce the energy consumption in relation to the services. Even in these best performers there is a potential for RECP measures like use of renewables, energy saving lighting system, energy management practices and others. Hotels with high capacity utilization (occupancy rate more than 60\%) have better energy performance as well. Hotels with higher energy consumption have a low occupancy rate indicator (20-50\% on yearly basis) and despite of the energy efficiency potential attention has to be paid to the business model and sustainability.

The agreed reference result is the maximum value for the first $20 \%$ of the enterprises $20 \mathrm{kWh}$ /overnight Fig.7). This benchmark is difficult to be achieved for the year-round city hotels for which another benchmark could be set $-40 \mathrm{kWh} /$ overnight (maximum value of the first $30 \%$ ). 


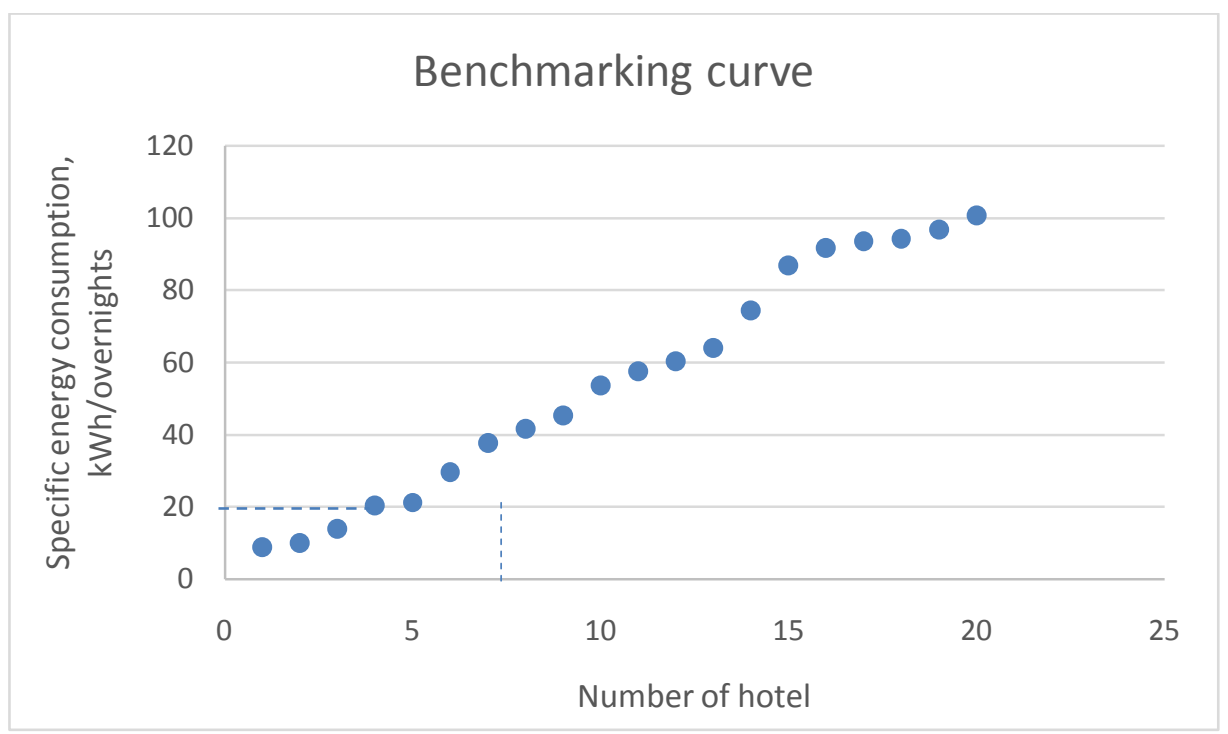

Fig. 7. Energy efficiency benchmarking curve

Source: In-plant assessment reports

Based on the experience in all countries it could be pointed out that benchmarking can be used as a management tool and allows to:

- $\quad$ Measure the gap to the "best performers";

- Identify opportunities for improvement by studying possibilities for implementation of good practices;

- $\quad$ Measure the improvement and maintain the achieved results.

\section{Implications}

The application of RECP approach in the accommodation sector demonstrates great potential in the Balkan countries, especially in terms of energy efficiency and waste segregation with substantial environmental benefits and economic savings.

The implementation of RECP methodology in hotels depends significantly on the commitment of owner, management and personnel, i.e. all operational levels and units. In the period of economic transition and crisis, climate change adaptation and sustainability consciousness, the hotel managers and the personnel show growing interest and active involvement in options identification and implementation of measures for improving the image and competitiveness of their hotel. All participants in the project realized that the process is continuous and requires step by step implementation of measures and communication to the local community and guests. Keeping personnel skills and awareness and making self-assessment and review of the results is also important for further success.

In general, small and medium sized tourism enterprises need consultancy and expert support to incorporate the RECP practices into their operational management and work. There are a lot of existing instruments and manuals for self-assessment and efficient use 
of recourses. However, there is always a need of initial impulse for seeking best practices applied in other hotels and to cooperate with hotelier associations and other stakeholders able to facilitate and support this process. This is also necessary for ensuring financial resources and improving the image of the hotel and the tourist destination.

\section{Acknowledgements}

We would like to thank to Mrs. Petra Schwager from UNIDO, who was the project manager of the Sustainable Tourism sub-project of the project "Regional networking for strengthening cooperation and fostering transfer and adaptation of resource efficient and cleaner production (RECP) in the countries of South-Eastern Europe". Special gratitude to all the national RECP experts and consultants who engaged actively in the training session and carried out in-plant assessments of hotels and to the tourism enterprises' owners and managers involved in the process of increasing their productivity and better environmental performance.

\section{References}

Albanian Institute of Statistics. http://www.instat.gov.al/en/themes/tourism.aspx?tab=tabs-5 [Online: accessed 9 May 2016]

Croatian Bureau of Statistics. http://www.dzs.hr/default_e.htm [Online: accessed 9 May 2016]

Georgiev, Z., D. Matev(2011) Self-Assessment Guide for Implementing Cleaner Production and Corporate Social Responsibility Measures in the Accommodation Sector (M. Assenova, ed.), SERC (in Bulgarian).

Georgiev, Z., M. Assenova. (2013) Resource efficiency practices in Bulgarian accommodation sector. Hotellink, vol. 14, number 21-22 .The College of Hotel Management, Belgrade, Serbia.

Hamele, H., S. Eckardt (2006) Environmental initiatives by European tourism businesses - Instruments, indicators and practical examples. University of Stuttgart.

Hotel Energy Solutions (2011), Hotel Energy Solutions: Fostering innovation to fight climate change Public Report. Hotel Energy Solutions project publications. http://cf.cdn.unwto.org/sites/all/files/docpdf/finalreport.pdf [Online: accessed 9 May 2016]

International Business Leaders Forum's travel and tourism programme and WWF-UK (2005) Why Environmental Benchmarking will help your Hotel.

Joint UNIDO and UNEP Programme on Resource Efficient and Cleaner Production, 2009. http://www.unep.or.jp/ietc/SPC/news-nov09/UNIDO_UNEP_RECP_Programme.pdf [Online: accessed 27 May 2016]

Luken, R., R. Berkel, H. Leuenberger, P. Schwager (2016) A 20-year retrospective of the National Cleaner Production Centres programme. Journal of Cleaner Production 112, 1165-1174.

Matev, D., M. Assenova. (2012) Application of corporate social responsibility approach in Bulgaria to support sustainable tourism development. Clean Technologies and Environmental Policy, Volume 14, Issue 6, Springer, pp 1065-1073.

Statistical Office of Montenegro. http://monstat.org/eng/page.php?id=43 [Online: accessed 9 May 2016]

Statistical Office of the Republic of Serbia. http://webrzs.stat.gov.rs/WebSite/Public/PageView.aspx?pKey=181 [Online: accessed 9 May 2016]

UNIDO Resource Efficient and Cleaner Production Toolkit .http://www.unido.org/index.php?id=o862050 [Online: accessed 9May 2016]

Vieira, L.C., F. G. Amaral (2016) Barriers and strategies applying Cleaner Production: a systematic review. Journal of Cleaner Production 113, 5-16.

World Travel and Tourism Council. Country reports. http://www.wttc.org/research/economicresearch/economic-impact-analysis/country-reports/ [Online: accessed 9 May 2016] 